$84 \%$ of the residues in the $\mathrm{E}$ and $\mathrm{F}$ helices are identical. This result implies that the residues in the $\mathrm{E}$ and $\mathrm{F}$ helices are conserved between the tetramer and dimer chains for some important purpose such as contact formation.

Thus, we decided to use the dimer electron density from our tetramer map as a search molecule in molecular replacement. Structure factors obtained from the inverse Fourier transform of the isolated density were used in rotation ${ }^{13}$ and translation ${ }^{14}$ function calculations against the dimer data. Unlike our previous molecular replacement calculations, these gave good solutions.

We tested the validity of this molecular replacement solution using various criteria. First, the $R$-value of $42.8 \%$ compares favourably with other successful solutions ${ }^{15,16}$. Second, dimer placement in the crystal showed no interpenetration between neighbouring molecules even though packing considerations were not included in the translation function (see Fig. 3). In addition, standard difference and 'haem-less'15 difference Fourier maps were calculated, examined and found to support this solution. Finally, an anomalous difference Patterson ${ }^{17}$ for native dimer crystals contained peaks at all positions for the expected iron-iron vectors.

The 'cooperative dimer' hypothesis of Antonini' ${ }^{7}$ and colleagues in the late 1960 s has been shown to be inapplicable to vertebrate haemoglobin ${ }^{8}$, in which the uncooperative $\alpha_{1} \beta_{1}$ dimer appears to move as an essentially rigid body. However, dimeric clam haemoglobin is cooperative, and a probable structural basis for that cooperativity has been revealed in the crystal structure. Because the same mode of subunit assembly occurs in the tetramer, it is likely that Antonini's cooperative dimer is the underlying cause of cooperativity also in tetrameric clam haemoglobin.

To ascertain how these structures change with the release of ligands and why the dimers do not form tetramers in solution, we intend to determine the structures of liganded and deoxy dimeric and tetrameric clam haemoglobins at high resolution.

We thank Drs Emilia Chiancone and Eraldo Antonini for drawing our attention to these interesting proteins and for providing us with purified dimeric and tetrameric haemoglobins; and Drs Janet Smith and Wayne Hendrickson for the symmetryaveraging programs and many helpful discussions. This work was supported by NIH grant AM 02528. W.E.R. was supported in part by NIH training grant GM 07231.

Received 14 February; accepted 3 May 1985.

1. Ohnoki, S., Mitomi, Y., Hata, R. \& Satake, K. J. Biochem., Tokyo 73, 717-725 (1973). 2. Djangmah, J. S., Gabbott, P. A. \& Wood, E. J. Comp. Biochem. Physiol, 60B, 245-250 (1978). 3. Furuta, H., Ohe, M. \& Kajita, A. J. Biochem., Tokyo 82, 1723-1730 (1977).

4. Como, P. F. \& Thompson, E. O. P. Aust. J. biol. Sci. 33, 643-652 (1980).

S. Chiancone, E., Vecchini, P., Verzili, D., Ascoli, F. \& Antonini, E. J. molec. Biol. 152, 577-592 (1981)

6. Ikeda-Saito, M. et al. J. molec. Biol. 170, 1009-1018 (1983).

7. Antonini, E. Science 158, 1417-1425 (1967).

8. Mills, F. C., Johnson, M. L. \& Ackers, G. A. Biochemistry 15, 5350-5362 (1976)

9. Como, P. F. \& Thompson, E. O. P. Aust. J. biol. Sci. 33, 653-664 (1980)

10. Furuta, H. \& Kajita, A. Biochemistry 22, 917-922 (1983)

11. Baldwin, J. \& Chothia, C. J. molec. Biol. 129, 175-220 (1979).

12. Phillips, S. E. V. J. molec. Biol. 142, 531-554 (1980).

13. Crowther, R. A. in The Molecular Replacement Method (ed. Rossmann, M. G.) 173-178 (Gordon \& Breach, New York, 1972).

14. Crowther, R. A. \& Blow, D. M. Acta crystallogr. 23, 544-548 (1967)

15. Ward, K. B., Wishner, B. C., Lattman, E. E. \& Love, W. E. J. molec. Biol. 98, 161-177 (1975). 16. Wishner, B. C., Ward, K. B., Lattman, E. E. \& Love, W. E. J. molec. Biol. 98, 179-194 (1975). 17. Rossmann, M. G. Acta crystallogr. 14, 383-388 (1961).

18. Bernstein, F. C. et al. J. molec. Biol. 112, 535-542 (1977).

\title{
MATTERSARISING
}

\section{A complex of copper (II)-montmorillonite with a modified cyclodextrin}

IN the article by Kijima et al. ${ }^{1}$, structural organization of intercalated mono- $(6-\beta$ aminoethylamino - 6 - deoxy)- $\beta$-cyclodextrin (CDen) has been deduced from the interpretation of electron paramagnetic resonance (EPR) spectra of oriented film samples (CDen-Cu(II)-montmorillonite).

However, the invariance of the EPR spectrum towards the variation of the angle between the film plane and magnetic field is indicative of a random orientation of the adsorbed $\mathrm{Cu}(\mathrm{II})$ complexes rather than a spatial organization. For both models proposed in Fig. $3 a$ and $b$, there should be a pronounced angular dependence of the spectrum with a maximum change at $45^{\circ}$ in 'structure $a$ ' and a vanishing component at $90^{\circ}$ in 'structure $b$ '.

Since the statements in this article are inferred from an erroneous spectrum interpretation, the conclusions about the lipid bilayer orientation remain questionable.

\section{Eidgenössische Technische}

HERBERT MOTSCHI

Hochschulen,

EAWAG, CH-8600 Dübendorf, Switzerland

\footnotetext{
1. Kijima, T., Tanaka, J., Goto, M. \& Matsui, Y. Nature 310
} $45-47(1985)$
KIJIMA ET AL. REPLY-We admit that we have misinterpreted the electron spin resonance (ESR) spectra given in Fig. 2 of our paper. It is true that these spectra are indicative of a random orientation of the adsorbed $\mathrm{Cu}$ (II) complexes rather than a spatial organization, as pointed out by Motschi. This indication, however, appears impossible in view of the stereochemistry of hydrated $\mathrm{Cu}(\mathrm{II})$ ions in $\mathrm{Cu}(\mathrm{I} \mathrm{I})$-montmorillonite ${ }^{1}$. By using $\mathrm{X}$ ray diffraction and scanning electron microscopy, we have re-examined the orientation of silicate layers in the film of CDen-Cu-montmorillonite used for ESR measurements. This re-examination leads us to conclude that the ESR spectra in Fig. 2 should be for a randomly oriented sample, not for an oriented film.

In considering the arrangement of intercalated CDen, ESR observations were used to justify two assumptions: (1) that the interlayer $\mathrm{Cu}(\mathrm{II})$ ion forms a coordination group $\left[\mathrm{Cu}(\mathrm{II})(e n)\left(\mathrm{H}_{2} \mathrm{O}\right)_{2}\right]^{2+}$ with a square configuration and (2) that this square plane is perpendicular to the silicate layers. The correct data support assumption (1), but are inefficient in proving the other. However, it does not mean that the structure model proposed is invalidated. This is because it seems reasonable to adopt the second assumption, and because the structure model was fundamentally deduced from the interpretation of data for the interlayer spacing and chemical composition of $\mathrm{CDen}-\mathrm{Cu}$ montmorillonite. Thus, our conclusions about the lipid bilayer orientation remain unchanged.

TSUYOSHI KIJIMA

JUNZO TANAKA

MASARU GOTO

YOSHIHISA MATSUI*

National Institute for Research

in Inorganic Materials,

Sakura-mura, Niiharigun,

Ibaraki, 305 Japan

* Department of Agricultural Chemistry, Shimane University,

Nishikawazu, Matsue, 690 Japan

1. Clementz, D. M., Pinnavaia, T. J. \& Mortland, M. M. J. chem. Phys. 77, 196 (1973).

\section{Matters Arising}

Matters Arising is meant as a vehicle for comment and discussion about papers that appear in Nature. The originator of a Matters Arising contribution should initially send his manuscript to the author of the original paper and both parties should, wherever possible, agree on what is to be submitted. Neither contribution nor reply (if one is necessary) should be longer than 500 words and the briefest of replies, to the effect that a point is taken, should be considered. 